九州大学学術情報リポジトリ

Kyushu University Institutional Repository

\title{
Sequence Analysis of Replication Origin of Plasmid pCTP4 in y-PGA-producing Bacillus Strain isolated from "Dan-douchi" in China
}

Iwamoto, Nobuhide

Microbial Genetics Division, Institute of Genetic Resources, Faculty of Agriculture, Kyushu University

Nakaj ima, Kazuhiko

Microbial Genetics Division, Institute of Genetic Resources, Faculty of Agriculture, Kyushu University

Saito, Hiroyuki

Microbial Genetics Division, Institute of Genetic Resources, Faculty of Agriculture, Kyushu University

Kaneko, Shinji

Microbial Genetics Division, Institute of Genetic Resources, Faculty of Agriculture, Kyushu University

他

https://doi.org/10.5109/24076

出版情報 : 九州大学大学院農学研究院紀要. 39 (3/4)，pp. 139-148，1995-03. Kyushu University バージョン：

権利関係 : 


\title{
Sequence Analysis of Replication Origin of Plasmid pCTP4 in y-PGA-producing Bacillus Strain isolated from "Dan-douchi" in China
}

\author{
Nobuhide Iwamoto, Kazuhiko Nakajima, Hiroyuki Saito, \\ Shinji Kaneko, Masahito Orima and Toshio Hara* \\ Microbial Genetics Division, Institute of Genetic Resources, Faculty of Agriculture, \\ Kyushu University, Fukuoka 812-81, Japan \\ (Received November 9, 2994)
}

\begin{abstract}
The structure of a 1.6-kbSphI-HindIII DNA sequence necessary and sufficient for the replication of a $6.3-\mathrm{kb}$ plasmid pCTP4 in y-PGA-producing Bacillus strain isolated from "dan-douchi" in China, which is responsible for y-polyglutamate production, has been characterized by using a trimethoprim-resistance gene derived form B. subtilis TTK24 chromosomal DNA as a selective marker. The 1.6-kb DNA sequence contains a rep gene encoding the protein (333 amino acids) essential for initiation of replication and a possible origin of replication. The predicted REP protein of pCTP4 has an overall homology with the REP proteins of pUH1 (73.9\% identity), pLS11 (87.4\%), pBAAl $(82.0 \%)$, and pFTB14 (76. $6 \%)$ in Bacillus spp., pLP1 (46.5\%) and pLAB1000 (32.4\%) in Lactobacillus spp., and pUB110 (34.8\%) and pC194 (21.9\%) in Staphylococcus aureus, but has not any similarity with the REP protein of the staphylococcal plasmid pT181.
\end{abstract}

\section{INTRODUCTION}

"Douchi" is a native fermented product made from whole soybeans in China. There are two kinds of "douchi" as a raw fermented product : without or with salt, $i$. e., "dan-douchi" and "xian-douchi." "Xian-douchi" is made from steamed soybean and salt using the koji molt of Aspergillus oryzae, and it is found to greatly resemble "hamanatto" in Japan. "Dan-douchi," the non-salty aging product of steamed soybean by the biological action of "natto" Bacillus-like microorganisms, is an adhesive fermented soybean with a noticeable odor of ammonia, and is, then considered to be the same as Japanese "natto" (Nakao, 1972). After fermentation, the raw "dan -douchi" is sun-dried, and then the dark-colored product is mixed with red pepper and ginger and aged for a while before being eaten. However, there are some striking and possesses some acidity, whereas "natto" is predominantly sticky and contains no acid (Bo, 1984).

We have reported that a 5.8-kilobase pair $(\mathrm{kb})$ plasmid designated $\mathrm{pUH} 1$, which encodes the y-polyglutamate-production stimulating factor $(p s f)$ gene responsible for y-polyglutamate production, is distributed widely in a number of Bacillus subtilis (natto) strains isolated from a fermented soybean food, "natto" (Hara et al., 1981 and 1983). B. subtilis and B. subtilis (natto) should be considered as one species, but these two bacilli are found to be classified separately on the basis of whether biotin is

\footnotetext{
* Corresponding author.
} 
essential for growth or not (Amaha et al., 195'2 ; Kida et al., 1963). y-Polyglutamate -producing Bacillus strain was isolated from "dan-douchi," which required biotin for growth and produced viscous substances, harbored a single plasmid pCTP4 $(6.3 \mathrm{~kb})$ (Hara et al., 1993). Recently, electron microscopy showed that a heteroduplex molecule between pUH1 and pLS11 of Bacillus subtilis IFO 3022 contains $1.11-\mathrm{kb}$ and 2.14- kb double-stranded termini (Hara et al., 1986). The 2.0-kb BstEII DNA fragment of pUH1, including the 1.11-kb double-stranded region, contains a 999-bp open reading frame, a promoter for the open reading frame, and a possible replication origin upstream of the promoter (Hara et al., 1991).

Analysis of the organization of various plasmids isolated from Gram-positive bacteria, such as pT181 (Projan and Novick, 1988), pC194 (Alonso and Tailor, 1987), pE194 (Dempsey and Dubnau, 1989), pFTB14 (Murai et al., 1987), pLP1 (Perez-Martin et al., 1988), pUB110 (Maciag et al., 1988), pBAAl (Devine et al., 1989), and pLAB1000 (Josson et al., 1990), has shown that all of the information necessary for replication is located on fragments of about $1.5 \mathrm{~kb}$ in length. These fragments harbor a rep gene, encoding a protein essential for the initiation of replication (REP) and its corresponding target site.

This communication reports that the 1.6-kb fragment of pCTP4 contains a 999-bp open reading frame, a promoter for the open reading frame, and a possible replication origin upstream of the promoter. Significant homology was observed between the amino acid sequence predicted from the 999-bp open reading frame and those of similar putative REP proteins encoded by the other well-known Gram-positive replicons.

\section{MATERIALS AMD METHODS}

Bacterial strains and plasmids. Escherichia coli JM101 and B. subtilis MI112 (arg -15 , leuB8, thr -5 , recE4) were used for a cloning host. The plasmids pCTP4 (Hara et al., 1993) and pATE1 (Hara et al., 1991) have been described previously, and plasmid pTL12 carrying the dihydrofolate reductase gene was kindly provided by Tanaka and Kawano (1980).

Media. LB broth and Panassay broth (Difco) for both B. subtilis and E. coli, Spizizen minimal medium for $B$. subtilis, and M9 minimal medium for $E$. coli were the same as those described previously (Hara et al., 1991). The cells carrying trimethoprim-resistant $\left(\mathrm{Tmp}^{\mathrm{r}}\right.$ ) plasmids were grown in AA medium (Tanaka and Sakaguchi, 1978) containing $1 \mathrm{mg} / \mathrm{ml}$ of Tmp.

DNA manipulations. Plasmid DNAs from B. subtilis were prepared and purified as described previously (Hara et al., 1991). Restriction endonucleases, T4 DNA ligase, and bacterial alkaline phosphatase were purchased from Takara Shuzo Co., Ltd., and used as recommended by the manufacture. Degradation of DNA with exonuclease Ba131 (Takara Shuzo Co., Ltd.) was done by the procedure of Legerski et al. (1978).

Methods for transformation and assessment of ori function. E. coli was transformed by the method of Morrison (1977), and B. subtilis was transformed by using protoplasted cells (Chang and Cohen, 1979).

DNA sequencing. DNA fragments were subcloned into plasmids pUC18 and 
pUC19, and DNA sequencing was done by the dideoxy chain termination method (Sanger et al., 1977) with Sequenase (United States Biochemical Corporation, Ohio, USA). Nucleotide and amino acid sequences were analyzed by the Hitachi DNASIS system.

\section{RESULTS AND DISCUSSION}

\section{Delimitation of the replication origin}

To facilitate the identification of the replication region of pCTP4, we used the trimethoprim-resistant $\left(\mathrm{Tmp}^{\mathrm{r}}\right)$ dihydrofolate reductase gene of $\mathrm{B}$. subtilis 168. A schematic presentation of the constructed plasmids is given in Fig. 1. The source of the dihydrofolate reductase-coding gene was a $\mathrm{Tmp}^{\mathrm{r}}$ strain, TTK24, of B. subtilis 168 (Tanaka and Sakaguchi, 1978) and has been cloned in the pBR322 plasmid of E.coli. DNAs from pTL12, carrying the $\mathrm{Tmp}^{\mathrm{r}}$ dihydrofolate reductase gene, which was constructed by Tanaka and Kawano (1980), and pBR322 were both treated with EcoRI and HindIII, mixed and ligated by T4 ligase, then pATEI was constructed. Plasmid pCTP4 was digested with SphI and HindIII, and then the ends were filled in with the Klenow fragment to generate blunt ends. The DNA fragments were mixed and ligated to the AatI site of pATE1 by T4 ligase, and then added to B. subtilis MI112 protoplasts. Several $\mathrm{Tmp}^{\mathrm{r}}$ colonies were obtained on AA agar plates containing Tmp $(1 \mathrm{mg} / \mathrm{ml})$ and one of them was used for further study. A plasmid, pNH3, carried in such a Tmpr colony had a molecular size of $8.2 \mathrm{~kb}$ (Fig. 1). The physical map of pNH3 using various restriction enzymes is shown in Fig. 1.

To define the boundaries of a functional unit of pCTP4 replication, the $1.6-\mathrm{kb} S p h \mathrm{I}$ - HindIII fragment of pCTP4 was digested with selected restriction endonucleases to obtain a set of overlapping DNA fragments. The digests filled in with Klenow fragment were ligated with pATE1, introduced into E.coli by transformation, and selected for ampicillin resistance. The plasmid DNA preparations containing each generated fragment were tested for replication in B. subtilis. The results are summarized in Fig. 2. The constructed plasmid with the 1.4-kbSphI-HaeIII fragment (fragment 2 in Fig. 2) could replicate in the B. subtilis host, but the recombinant plasmid preparations containing the small fragments (fragment 3 and 4 in Fig. 2) could not replicate.

\section{Nucleotide sequence of the replication region}

The nucleotides of the 1.6-kbSphI-HindIII fragment were sequenced by the method of Sanger (1977). Though the strategy is not shown, the nucleotides of both strands were sequenced using numerous restriction fragments to give enough overlapping regions (Fig. 3). Looking for possible open reading frames (ORFs), we found only one large frame (Fig. 2) designated rep, which consisted of 999 bp and encoded a protein molecule with 333 amino acids with a $M_{\mathrm{r}}$ of 38,582. Several conserved regulatory sequences similar to the E.coli and Bacillus consensus promoter sequences (McLaughlin et al., 1981) were observed 5' upstream to the rep ORF.

PlasmidpNH3 was digested with $B g l \mathrm{II}$ and then treated for $20 \mathrm{~min}$ with exonuclease Ba131 under the conditions in which about 50 bp per min were removed from 


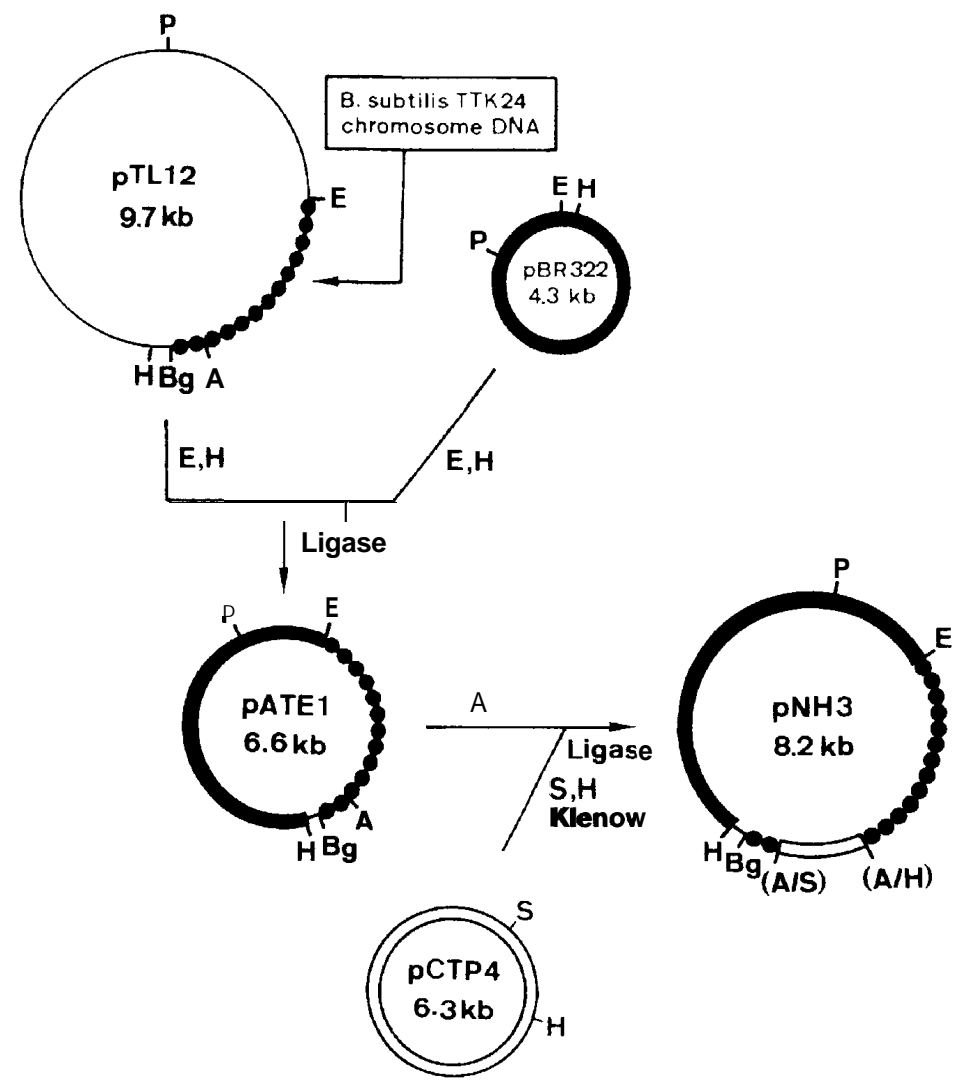

Fig. 1. Derivation of plasmids used in this study.

The chain of solid circles in the diagram indicates the DNA segment containing the Tmp' gene of B. subtilis TTK24. Heavy and thin lines represent the regions of pBR322 and pTL12, respectively. Double lines represent the DNA fragment of pCTP4. A, Aat I Bg, BglII ; E, Eco RI ; H, HindIII ; P, PstI ; S, SphI.

each end of the DNA molecule. After ligation by T4 ligase, the DNA was transformed into E. coli and subsequently introduced into B. subtilis by protoplast transformation. Tmp $\mathrm{p}^{\mathrm{r}}$ transformants, which contain $1.4-\mathrm{kb}$ fragment 5 in Fig. 2, were obtained at high efficiencies with a 168 -bp deletion plasmid generated with Bal31 (fragment 5 in Fig. 2), while no transformants were obtained with a similar 255-bp deletion plasmid (fragment 6 in Fig. 2). It suggests that the putative replication origin of pCTP4 is between position 168 and 255 . To discover the sequences essential for replication, a homology search was done to find whether there are sequences within this region conserved in the registered Gram-positive replicons. A 34-bp sequence was conserved in four plasmids, pCTP4,pLS11,pUH1,pBAA1 and pFTB14 in Bacillus spp. (Fig. 4), and the 14-bp sequence within this region was conserved in all eight plasmids in Gram -positive bacteria including Lactobacillus spp. and Staphylococcus spp. This conserved 14 -bp sequence is found in the 55-bp region of pC194 shown by Gros et al. (1987) to 


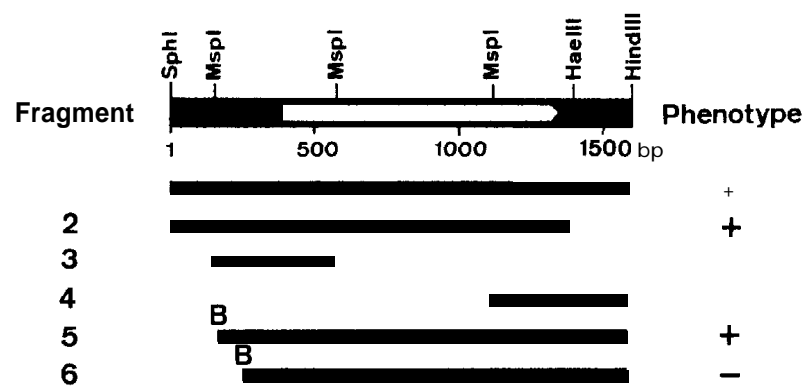

Fig. 2. Structure and replication activity of the derived fragments of the $1.6-\mathrm{kb}$ ori fragment.

The open arrow in the restriction map indicates an open reading frame found in the sequence data (see Fig. 3). + and - indicate, respectively, ability and inability to replicate in the $B$. subtilis host. Derivatives were made by deletion with the indicated restriction enzyme or by Ba131 digestion (B) from the $B g l \mathrm{II}$ site of $\mathrm{pNH} 3$.

have origin activity. Within this 14-bp sequence, in addition, the sequence CTTGATA is the sequence at which nicking of the plus-strand occurs in the initiation of replication of the coliphage $\phi \mathrm{X} 174$ (Shlomai and Kornberg, 1980), and this conserved sequence was found in a hairpin region of $\phi \mathrm{X} 174$.

\section{Amino acid sequence homology of pCTP4 REP protein with different Gram-positive} replication proteins

The amino acid sequence of the REP protein coding region of pCTP4 was compared with a number of amino acid sequence of proteins registered in GenBank by the homology search system GENAS (Kuhara et al., 1984). Homologies between the predicted amino acid sequence of the REP protein of pCTP4 and those of the REP protein of pUH1, pLS11, pBAA1, pFTB14, pLP1, pLAB1000, pUB110 and pC194 are illustrated in Fig. 5. The REP protein encoded on pCTP4 showed a substantial degree of homology to three REP proteins in Bacillus plasmids: $87.4 \%$ identity with REPpLS11, 82.0\% with REPpBAA1, 76.6\% with REPpFTB14, and $73.9 \%$ with REPpUH1. The REPpCTP4 is similar to REPpLP1 (46.5\% identity) and REPpAB1000 (32.4\%) from lactic acid bacteria but also to REPpUB110 (34.8\%) and REPpC194 (21. 9\%) from S. aureus. The REP protein of $\mathrm{pFTB} 14$ stretches for $1,017 \mathrm{bp}$, a promoter region for rep expression, and a possible replication origin for rep expression, which is upstream of the promoter. The rep product is trans-active and essential for plasmid replication (Murai et al., 1987). The tyrosine, which acts as an active site of REP in the rolling circle mechanism (Van Mansfeld et al., 1986), was conserved in all of the Gram-positive initiation proteins (Fig. 5). Khan et al. (1982) identified the start site of pT181 DNA synthesis within a 127-bp segment and showed that a $168 \mathrm{bp}$ segment containing the replication start site is enough to initiate unidirectional replication. Furthermore, like REP protein of pT181 (Projan and Novick, 1988), the protein of the E. coli plasmid R6K (Stalker et al., 1982 ; Germino and Bastia, 1982) does not 
SphI 50
5' -GCATGCTGCGGAGATAACACGGGCTGCTGCGCGAATGATGCGGGCATGGGTGCGTTGATCGTGCCGAGACTGAAAA $\begin{array}{cr}100 & 150 \\ \text { AGCCGATTTTTGAAAAAAAAATCCCCCCCCTGCGAAGAATGGTTTTGATCTTTGGGTTTTAGGTTTAAAAAAAGCC }\end{array}$

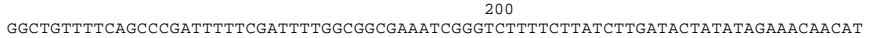

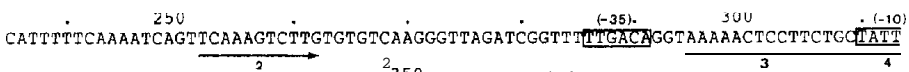

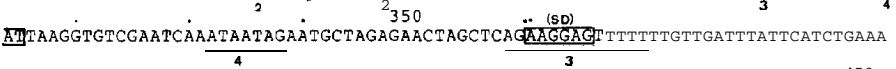
40040450 ATG ATT Ama GCA TCC TCG AAG ATA AAA CCG CAA CAG GTA AAA AGC GGG ATt GGA AGG GGA
Met Ile Ile Ala Ser Ser Lys Ile Lys Pro Gln Gln Val Lys Ser Gly Ile Gly Arg Gly 500

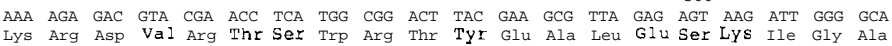
550

CCT TAC TAT GGC AAA AAG GCT GCC AAA CTA ATT AGT TGT GCA GAG TAT CTT TCG TTT AAG Pro Tyr Tyr Gly Lys Lys Ala Ala Lys Leu Ile Ser Cys Ala Glu tyr Leu Ser Phe Lys 600 AGA GAC CGG AGA CGC GGC AAg TTA AAA CTG TAT CAA GCC CAT TTT TGT AAA GTG AGG TTA
Arg Asp Arg Arg Arg Gly Lys Leu Lys Leu Tyr Gln Ala His Phe Cys Lys Val Arg Leu 650 TGC CCG ATG TGT GCG TGG CGT AGg TCG TTA AAA ATt GCT TAT CAC RAT AAg TTG ATC GT Cys Pro Met Cys Ala trp Arg Arg Ser Leu Lys Ile Ala tyr His Asn Lys Leu Ile Va $700 \quad 750$ GAG GAA GCC AAT CCG CAG TAC GGT TCT GGA TGG ATT TTT CTC ACG CCG ATG GTT CGG AAT Glu Glu Ala Asn Pro GIn Tyr Gly Ser Gly Trplle Phe Leu Thr Pro Met Val Arg Asn GTC GAG GGA GAA CGG CTG AAg CCA CAA ATT TCT GAG ATG CAT AAA GGA TTT AGG AAA CTG GTC GAG GGA GAA CGG CTG AAG CCA CAA ATT TCT GAG ATG CAT AAA GGA TTT AGG AAA CTG
Val Val Gly Glu Arg Leu Lys Pro Gln Ile Ser Glu Met His Lys Gly Phe Arg Lys Leu TTC CAG TÁC AAA AAR GTA AAA ACT TCG GंTT GCT GGA $\stackrel{850}{\text { TTT }}$ TTC AGA GCí TTA GAG ATT ÁCC Phe Gln Tys Lys Lys val Lys Thr Ser Val Ala Gly Phe Phe Arg Ala Leu GluIle Thr AAA AAT CAT GAA GAA GAT ACA TAC CAT CCT CAT TTT CAT GAG TTG ATA CCA GTA AGG AAA Lys Asn His Glu Glu Asp Thr Tyr His pro His phe His Glu Leu Ile Pro val Arg lys 950 AAT TAT TTT GGG AAA AAC TAT ATT AAG CAG TCG GAG TGG ACG AGC CTT TGG AAA AAG TCG

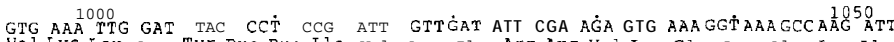

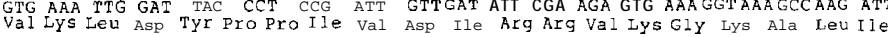
GAC GCT GAA CTG ATT GAA AGC GAT GTG CGG GAA GCA ATG ATG GAG CAA AAA GCT GTT CTC Asp Ala Glu Leu Ile Glu Ser Asp Val Arg Glu Ala Met Met Glu Gin Lys Ala Val Leu GAA ATT Tं́ AAA TAT CĆ GTT AAG GAT ACG GAT GTT GTG CGC GGC AAT AAG GTG ACT GAA Glu Ile Ser Lys Tyr pro val lys Asp Thr Asp Val Val Arg Gly As, Lys Val thr Glu 1200
GAC ATt CTG AAC GCG GTG CTT TAT TTG GAT GAT GCG TTG GCA GCT CGA AGg TTA ATT GGA GAC ATT CTG AAC GCG GTG CTT TAT TTG GAT GAT GCG TTG GCA GCT CGA AGG TTA ATT GGA
Asp Ile Leu Asn Ala Val Leu Tyr Leu Asp Asp Ala Leu Ala Ala Arg Arg Leu Ile Gly

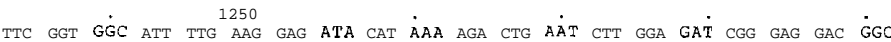
Phe Gly Gly Ile Leu Lys Glu Ile His Lys Arg Leu Asn Leu Gly Asp Arg Glu Asp Gly 1300
GAT CTG GTC AAG ATT GAG GAA GAA GAT GAC GAG ATT GCA AAC GGC GCA TTT GAG GTT ATG Asp Leu Val Lys Ile Glu Glu Glu Asp Asp Glu Ile Ala Asn Gly Ala Phe Glu Val Met

GCT TAT TÉG CAT CCT GGC ATT AAA AAT TAC ATA ATC ÁGA TAA AABGCAGGCOIII. Ala Tyr Trp His Pro Gly Ile AAs Asn Tyr Ile Ile Arg *AA AAAGAGGCCTTGTTCCTGCTTm TITTATACTCTAÁTAGTCAAATGTGTGAAATATGTTTTGTTCGTTTTTTATCTTTGTAGCTITTTATGATTAATTGTC 1500 1550 TATGATAACCTAGGGAATCTTTACATTGTCTGTGTIGAATAGTTACATAAACTGCTtTGCTCTTAGGATAGTTTAAATA HINAII I 1607

Fig. 3. Nucleotide sequence of the $1.6-\mathrm{kbSphI}-$ HindIII DNA fragment.

Nucleotide residues are numbered in the 5'-to-3' direction, beginning with the 5'-end residue originated from the $S p h \mathbf{I}$ site. The deduced amino acid sequence is given below the nucleotide sequence. Putative promoter elements $(-35,-10$ and the ribosome binding site) are underlined. 


\begin{tabular}{l}
\multicolumn{1}{c}{ A } \\
pCTP 4 \\
pUH1 \\
pLS11 \\
PGAA1 \\
pFTB14 \\
pLP1 \\
pLAB1000 \\
pUB110 \\
pC194 \\
$4 \times 174$
\end{tabular}

\begin{tabular}{|c|c|c|}
\hline$\rightarrow$ & $\longrightarrow$ & \\
\hline -GAAATCGGGTCTT & TTCTTATCTTGATA & CTATATAGA-3' \\
\hline GAAATCGGGTCTT & TTCTTATCTTGATA & CTATATAGA \\
\hline CAAATCGGGTCTT & TTCTTATCTTGATA & CTATATAGA \\
\hline CAAATCGGGTCTT & TTCTTATCTTGATA & CTATATAGA \\
\hline AAAATCGGGTCTT & TTCTTATCTTGATA & CTATATAGC \\
\hline $\operatorname{tTt} \mathrm{c}$ & TTCTTATCTTGATA & CTATta \\
\hline GTtTc & TTCTTATCTTGATA & CTActa \\
\hline GTtcT & TTCTTATCTTGATA & Catata \\
\hline tTt & TTCTTATCTTGATA & aTAagg \\
\hline & & \\
\hline
\end{tabular}

B

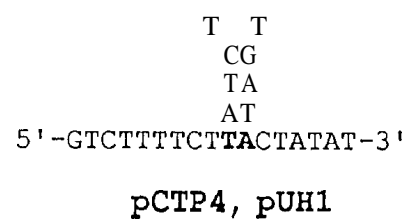

Fig. 4. (A) Homology at the origin for plus-strand synthesis among several plasmids in Gram-positive microorganisms. The nucleotides in boxes are conserved well among them. The sequence CTTGATA, which is the site at which nicking of the plus strand occurs in phage $\phi \mathrm{X} 174$, are boldface. The DNA bond between nucleotides $\mathrm{G}$ and $\mathrm{A}$ will be nicked by the REP protein and is indicated by an arrow. (B) Hairpin structure of the pC194 origin region proposed by S. D. Ehrlich and the predicted structure of origin region of plasmids pCTP4 and pUH1.

have any significant homology in its amino acid sequences with those of the REP proteins of pCTP4,pUH1, pLS11 and also pFTB14 deduced from the ORFs (data not shown). Comparison of dendrograms made on the basis of 16SrRNA hybridizations and the percentage of homology on REP protein are illustrated in Fig.6. The degree of homology of REPpCTP4 with the REP proteins of pLP1 and pLAB1000 in Lactobacillus spp. strains was almost the same as those with the REP proteins of pUB110 and pC194 in S. aureus. Taxonomic studies (based on the 16S rRNA similarities) showed that Bacillus spp. and S. aureus strains are more closely related to each other than Staphylococcus spp. and Lactobacillus spp. (Stackebrandt and Teuber, 1988). The plasmid homologies suggest an exchange of plasmid replicons by recent horizontal transfer through the different genera, including B. subtilis (natto).

\section{REFERENCES}

Alonso, J. C.and R. H. Tailor 1987 Initiation of plasmidpC194 replication and its control in Basillus subtilis. Mol. Gen. Genet., 210: 476-484 


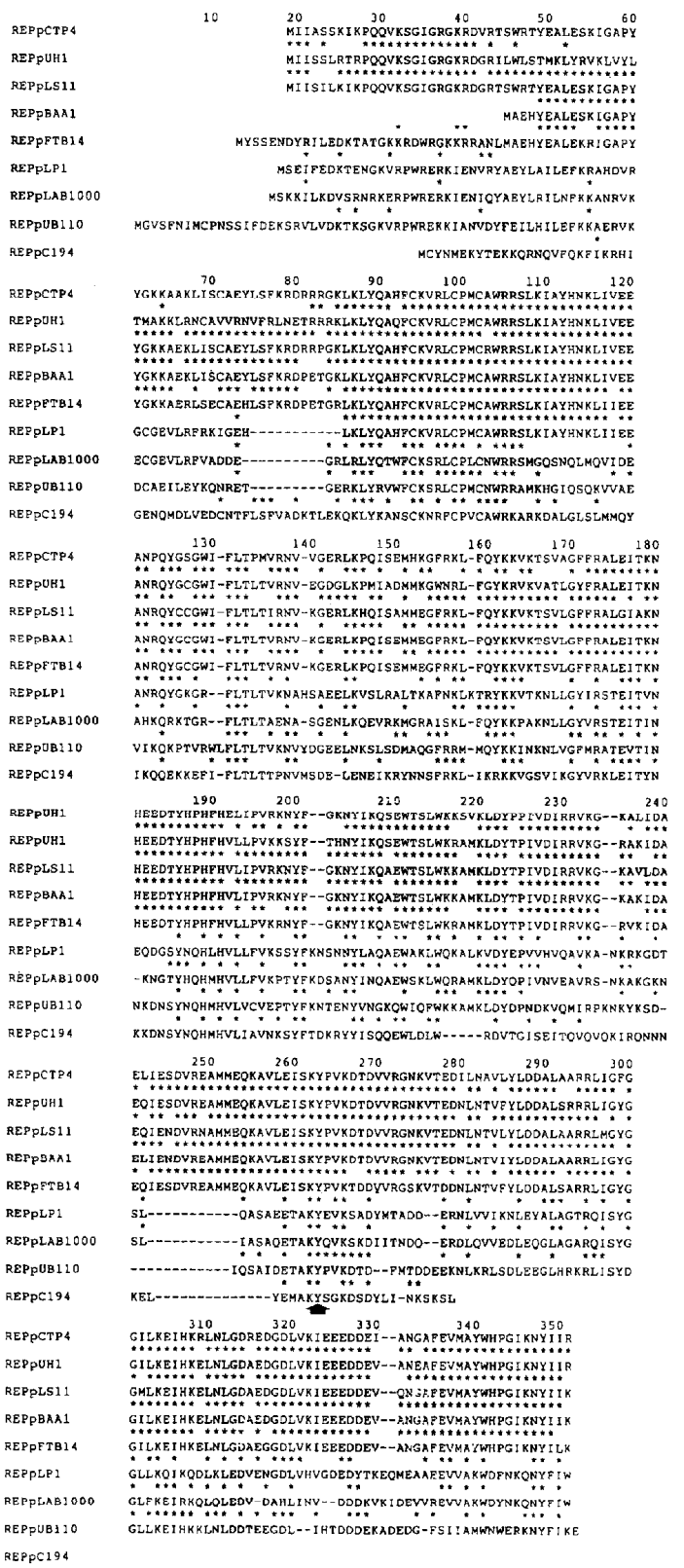

Fig. 5. Amino acid sequence comparison of the REPpCTP4 protein with different Gram-positive replication proteins.

The original names of these proteins have been replaced by REP, followed by a letter code indicating the plasmid from which they originate. The amino acid identities with several plasmids in Gram-positive microorganisms with REPpCTP4 are indicated $(*)$. Amino acid numbers follow the sequence of the REP protein from the amino-terminal methionine to the carboxy terminus. Gaps have been inserted to gain maximum matching. The one-letter amino acid code has been used. The tyrosine residue (marked with arrow) probably involved in the binding of the REP protein to the DNA is indicated by an arrow. 


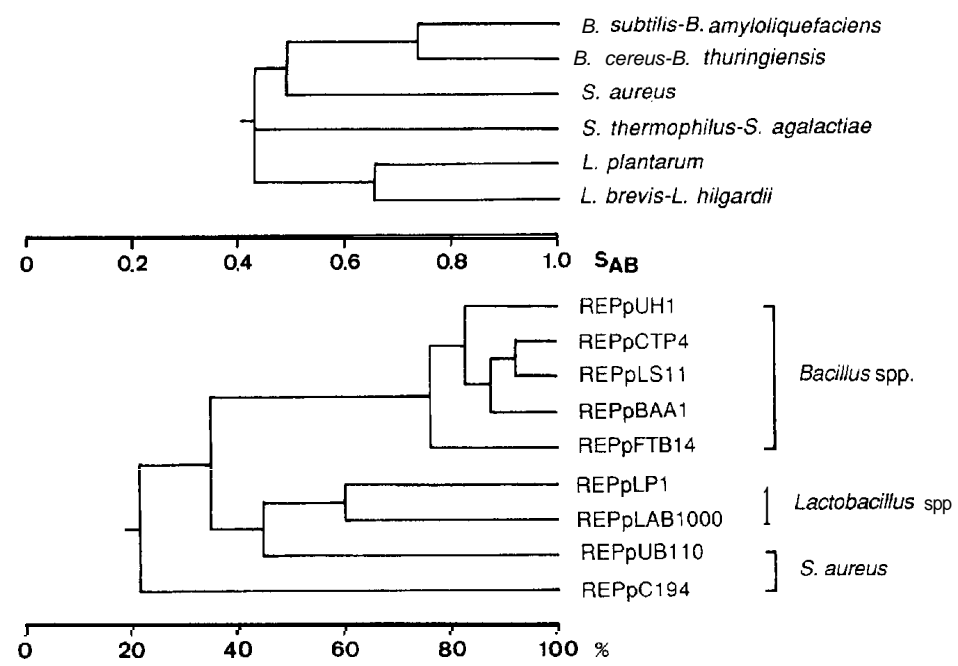

Fig. 6. Comparison of dendrograms made on the basis 16S rRNA hybridizations (A) and the percentages of homology on Rep proteins among several plasmids in Gram-positive microorganisms (B).

The microorganisms from which the plasmids originate are shown. Dendrograms were made by the unweighted average pair group method (Sneath and Sokal, 1973).

Amaha, M. and K. Sakaguchi 1952 Bacillus zoku saikin no hanshoku saibou narabini houshi no eiyouyoukyu nituite. Nippon Nougeikagaku Kaishi, 26 : 353-359 (in Japanese)

Bo, T.A. 1984 Origin of douchi, and its production technique. Part 2. Nippon Jozo Kyokai Zasshi, 79 : 395-402 (in Japanese)

Chang, S. and S. N. Cohen 1979 High frequency transformation of Bacillus subtilis plotoplasts by plasmid DNA. Mol. Gen. Genet., 168: 111-115

Dempsey, L. A. and D. A. Dubnau 1989 Localization of the replication origin of plasmid pE194. J. Bacteriol., 171 : 2866-2869

Devine, K. M., S. T. Hogan, D. G. Higgins and J. McConnell 1989 Replication and segregational stability of Bacillus plasmid pBAA1. J. Bacteriol., 171 : 1166-1172

Germino, J. and D. Bastia 1982 Primary structure of the replication initiation protein of plasmid R6K. Proc. Natl. Acad.Sci., U. S. A., 79: 5475-5479

Gros, M. F., H. te Riele and S. D. Ehrlich 1987 Rolling circle replication of single-stranded DNA pC194. EMBO J., $6: 3863-3869$

Hara, T., A. Aumayr and S. Ueda 1981 Characterization of plasmid deoxyribonucleic acid in Bacillus natto: evidence for plasmid-linked PGA production. J. Gen. Appl. Microbiol., 27 : 299 $-305$

Hara, T., A. Ishizaki and S. Ueda 1986 Formation of heteroduplex molecules between plasmids pUH1 and pLS11 in polyglutamate- producing Bacillus strains. Agric. Biol. Chem., 50 : 2391-2394

Hara, T., S. Nagatomo, S. Ogata and S. Ueda 1991 Molecular structure of the replication origin of a Bacillus subtilis (natto)plasmid,pUH1.Appl. Environ. Microbiol., $57: 1838-1841$

Hara, T., K. Nakajima, H. Saito, A. Ishizaki, S. Ogata and S. Ueda 1992 Sequence analysis of replication origin of plasmidpLS11 of Bacillus subtilis IFO 3022. Biosci. Biotech. Biochem., 56 : 223 $-227$

Hara, T., S. Ogata and S. Ueda 1993 Plasmid distribution in $\gamma^{-}$polyglutamate-producing Bacillus strains isolated from "dan-douchi," a "Natto"-like non-salty fremented soybean food in China. 
J. Gen. Appl. Microbiol., 39 : 75-82

Hara, T., J. R. Zhang and S. Ueda 1983 Identification of plasmids linked with polyglutamate production in Bacillus subtilis (natto). J. Gen. Appl.Microbiol., 29: 345-354

Josson, K., P. Soetaert, F. Michiels, H. Joos and J. Mahillon 1990 Lactobacillus hilgardii plasmid pLAB1000 consists of two functional cassettes commonly found in other Gram-positive organism. J. Bacteriol., 172 : 3089-3099

Kahn, S. A., G. K. Adler and R. P. Novick 1982 Functional origin of replication of pT181 plasmid DNA is contained within a 168-base-pair segment. Proc. Natl.Acad. Sci., USA, 79: 4580-4584

Kida, S., W. Hashida and S. Terumoto 1963 Natto oyobi nattokin nikansuru eiyougakuteki kenkyu. HakkokogakuKaishi, $34: 542-546$

Kuhara, S., F. Matsuo, S. Futamura, A. Fujita, T. Shinohara, T. Takagi and Y. Sakaki 1984 GENAS : a database system for nucleic acid sequence analysis. Nucleic Acids Res., 12 : 89-99

Legerski, R. J., J. L. Hodnett and H. B. Gray Jr. 1978 Extracellular nucleases of Pseudomonas BAL31. III. use of the double-strand deoxyribonuclease activity as the basis of a convenient method for the mapping of fragments of DNA produced by cleavage with restriction enzymes. Nucleic Acids Res., 5: 1445-1464

Maciag, I. E., J. -F. Viret and J. C. Alonso 1988 Replication and incompatibility properties of plasmid pUB110 in Bacillus subtilis. Mol. Gen. Genet., 212: 232-240

McLaughlin, J. R., C. L. Murray and J. C. Rabinowitz 1981 Unique features in the ribosome binding site sequence of the Gram-positive Staphylococcus aureus $\beta$-lactamase gene. J.Biol. Chem., 256 : 11283-11291

Morrison, D. A. 1977 Transformation in Escherichia coli: cryogenic preservation of competent cells. J. Bacteriol., 132 : 349-351

Murai, M., H. Miyashita, H. Araki, T. Seki and Y. Oshima 1987 Molecular structure of the replication origin of Bacillus amyloliquefaciens plasmidpFTB14.Mol. Gen.Genet., 210 : 92-100

Nakao, S. 1972 Ryori no Kigen. NHK Press, Tokyo, pp.121 (in Japanese)

Perez-Martin, J., G. H. del Solar, A. G. de la Campa and M. Espinosa 1988 Three regions in the DNA of plasmidpLS1 show sequence-directed static bending. Nucleic Acids Res., 16 : 9113-9126

Projan, S. J. and R. Novick 1988 Comparative analysis of five related staphylococcal plasmids. Plasmid, $19:$ 203-221

Sanger, F., S. Nicklen and A. R. Coulson 1977 DNA sequencing with chain-terminating inhibitors. Proc. Natl. Acad. Sci., U. S. A., 74: 5463-5476

Shlomai, J. and A. Kornberg 1980 An Eschrichiacoli replication protein that recognizes a unique sequence within a hairpin region in $\phi$ X174 DNA. Proc. Natl. Acad, Sci., U. S. A., 77 : $799-803$

Sneath, P. A. and R. R. Sokal 1973 Numerical Taxonomy. The Principle and Practice of Numerical Classification. W. H. Freeman \& Co., San Francisco

Stackebrandt, E. and M. Teuber 1988 Molecular taxonomy and phylogenetic position of lactic acid bacteria. Biochimie, $70: 317-324$

Stalker, D. M., R. Kolter and D. R. Helinski 1982 Plasmid R6K DNA replication. J. Mol. Biol., 161: $33-43$

Tanaka, T. and N. Kawano 1980 Cloning vehicles for the homologous Bacillus subtilis host-vector system. Gene, 10: 131-136

Tanaka, T., M. Kuroda and K. Sakaguchi 1977 Isolation and characterization of four plasmids from Bacillus subtilis. J. Bacteriol., 129 : 1487-1494

Tanaka, T. and K. Sakaguchi 1978 Construction of a recombinant plasmid composed of B. subtilis leucine gene and a B. subtilis (natto) plasmid: its use as cloning vehicle in B. subtilis 168. Mol. Gen. Genet., 165: 269-276

Van Mansfeld, A. B. M., H. A. A. M. Teeffelen, P. D. Baas and H. S. Janzs 1986 Two juxtaposed tyrosyl-OH groups participate in $\phi \mathrm{X} 174$ gene a protein catalyzed cleavage and ligation of DNA. Nucleic Acids Res., 14 : 4229-4238 